\title{
Study of friction stir processed zone under different tool pin profiles in pure copper
}

\author{
S. Cartigueyen ${ }^{1}, \mathrm{~K}$. Mahadevan ${ }^{2}$ \\ ${ }^{I}$ Research Scholar, Dept. of Mechanical Engineering, Pondicherry Engineering College, Pondicherry - \\ 605014,India \\ ${ }^{2}$ Professor, Dept. of Mechanical Engineering, Pondicherry Engineering College, Pondicherry -605014, India.
}

\begin{abstract}
Friction Stir Processing (FSP) is a solid-state surface modification technique to alter the properties of metals and alloys. This work studies the effect of FSP on pure copper with six different tool pin profiles ( plain cylindrical, threaded cylindrical, triflute, triangle, square and hexagonal) at low-heat input condition. The tool rotational speed and tool traverse speed were kept constant to maintain the low heat input. Temperature distribution, microstructure, microhardness and tensile strength were analyzed to evaluate the modifications occurred in the mechanical properties. From the investigation, it is observed that threaded cylindrical pin profile tool is more effective in bringing about a favourable mechanical modification in pure copper than other pin profiles under low-heat input condition.
\end{abstract}

Key words: Copper, FSP, Heat generation, Mechanical properties, Microstructure, Tool pin profile.

\section{Introduction}

Copper and its alloys have found extensive applications because of its high thermal and electrical conductivity, plasticity, softness and formability. However, copper in pure form has poor strength, wear and fatigue resistance and hence is unsuitable for high end applications like contact terminals of electrical switches and sliding surfaces. Friction Stir Processing (FSP) overwhelmed the above limitations of the pure copper. FSP is a cost-effective, energy efficient and a one-step processing route based on the principle of Friction Stir Welding (FSW). It is a unique process to modify the microstructure and other mechanical properties at selective locations [1]. The microstructure and mechanical properties of the processed zone can be accurately controlled by optimizing the tool design, process parameters [2-4].

The degree of plastic deformation and the heat generation during FSP are the dominant factors determining grain refinement at processed zone $[5,6]$. Therefore, it is important to understand about the temperature distribution during the FSP. Xie et al [7] have been reported that a decrease in heat input can reduce the size of the recrystallized grains in FSW copper significantly and observed that hardness and strength of the copper was improved at low-heat input conditions. Khodaverdizadeh et.al [8] have investigated the effect of tool pin profile on FSWed pure copper joints. The results revealed that square pin profile produced finer crystallized grain structure, higher degree of plastic deformation at the stir zone. Surekha and Els-Botes [9] have also developed a high strength and high conductivity copper by FSP at low-heat input condition and concluded that peak temperature is the dominant factor determining grain size in their study. Pin profiles can influence the material flow path and degree of plastic deformation [3, 8].Thus, the availability of literatures focusing on the effect of FSP tool pin profiles on the formation of stir zone in pure copper at low-heat input conditions are very scarce.

Hence, in this investigation, an attempt has been made to study the effect of tool pin profiles on the formation of stir zone in pure copper at low heat input condition. FSP of copper is carried out with a constant rotation and traverse speed with six different FSP tool pin profiles. The effects of FSP tool pin profile on the formation of stir zone are analyzed by heat generation study during processing and by conducting microhardness and tensile tests after post processing. Microstructures of the FSPed and as received copper were compared to understand the mechanism behind the modification in the mechanical properties.

\section{Experimental Work}

In this study, commercial pure copper plates of $100 \mathrm{~mm}$ length, $50 \mathrm{~mm}$ width and $6 \mathrm{~mm}$ thickness were used. A conventional vertical milling machine (3HP) was used to perform FSP on copper plates. The high carbon high chromium $(\mathrm{HCHCr}$ ) tool steel was used to fabricate FSP tools which were subsequently hardened to 58 HRC. Fig. 1 shows the six different tool pin profiles used to perform FSP on copper plates. The Table.1 lists the tool geometry and the process parameter values. 


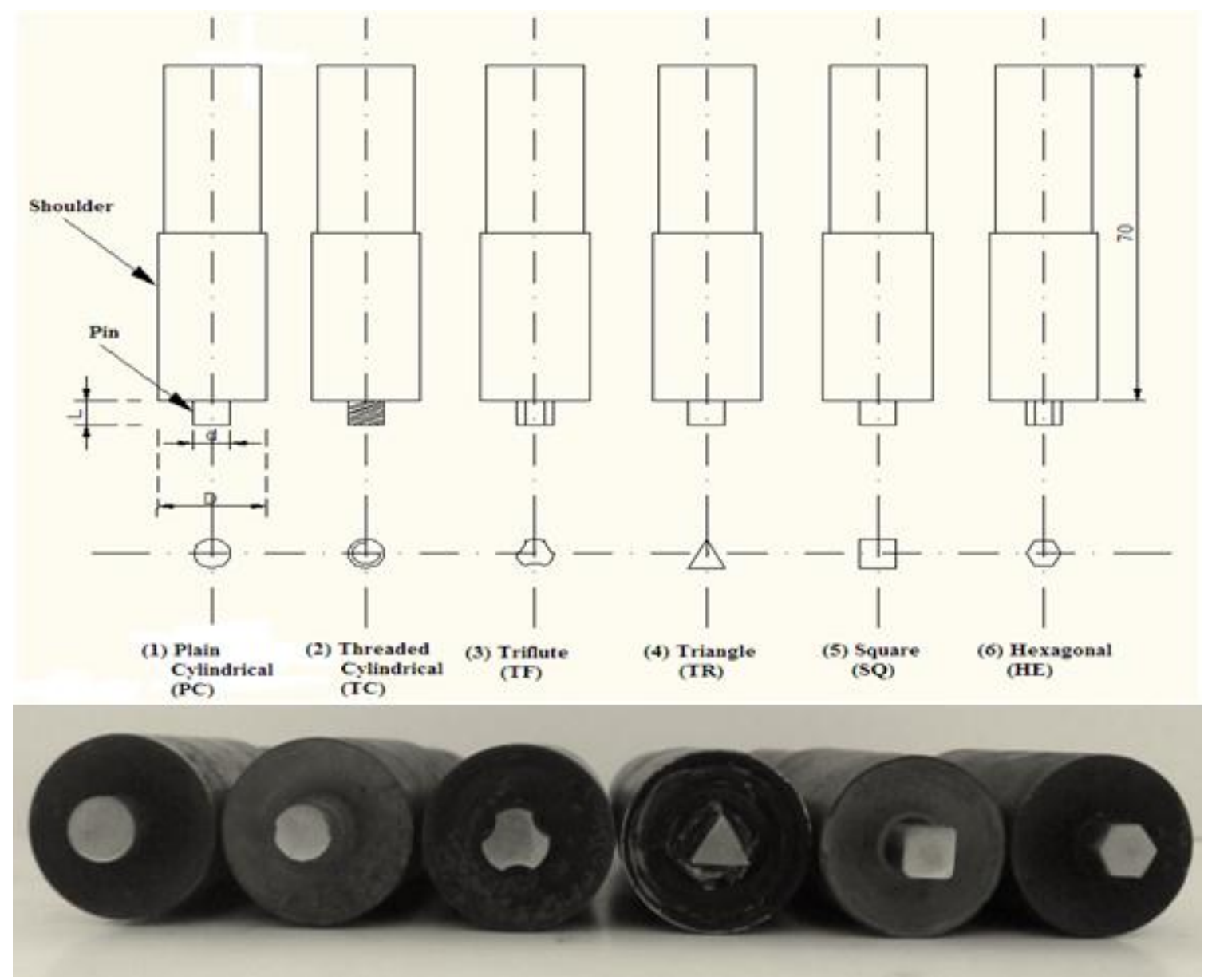

Fig. 1 Straight flat-bottom FSP tool pin profiles with its geometry used in this investigation

Table 1 FSP parameters and tool geometry

\begin{tabular}{|l|l|}
\hline Tool Rotation speed & $350 \mathrm{rpm}$ \\
Tool Traverse speed & $50 \mathrm{~mm} / \mathrm{min}$ \\
Tool shoulder diameter (D) & $18 \mathrm{~mm}$ \\
Tool pin diameter (d) & $6 \mathrm{~mm}$ \\
D / d ratio of tool & 3.0 \\
Pin length (L) & $5.70 \mathrm{~mm}$ \\
Tool inclined angle & 0 degree \\
Shoulder plunge into the surface of base metal & $0.1 \mathrm{~mm}$ \\
Pitch of threaded pin & $1.0 \mathrm{~mm}$ \\
Included angle of threaded pin & 60 degree \\
\hline
\end{tabular}

The FSP tool was mounted on the arbor of vertical milling machine (VMM) and the copper plate is fixed on the machine table using a special fixture. Once the tool pin was plunged into the copper plate, the automatic feed mechanism was engaged for further travel with preset feed rate. A constant shoulder plunge of $0.1 \mathrm{~mm}$ was maintained throughout the process. The experiments were conducted with six different tools at 350 $\mathrm{rpm}$ as tool rotation speed and $50 \mathrm{~mm} / \mathrm{min}$ as traverse speed to achieve the low heat input condition during the FSP on the copper plates. The heat input condition was monitored by embedded thermal couples in the copper plate. K-type thermocouples (1.6 mm diameter) were used in this study. Fig.2 shows the locations of five thermocouples which were embedded at the bottom of the plate, one in the middle of stir zone, one each in advancing and retreating side of stir zone and two in heat affected zones (HAZ) to assess the temperature variations across the stir zone and $\mathrm{Cu}$ plate. Thermocouple output was recorded directly from the digital temperature recorder.

The base material and the FSP zones formed by different pin profiles were examined by optical microscopy as per ASTM standards. Everone - MH5C Vickers microhardness tester was used to measure the microhardness at a constant load of $0.025 \mathrm{Kgf}$ and a dwell period of 15 seconds. Tensile samples were machined in longitudinal direction parallel to the FSP direction and tests were conducted at room temperature as per ASTM (E8M) standards on base metal and FSPed samples using a 5 ton tensile testing machine. 

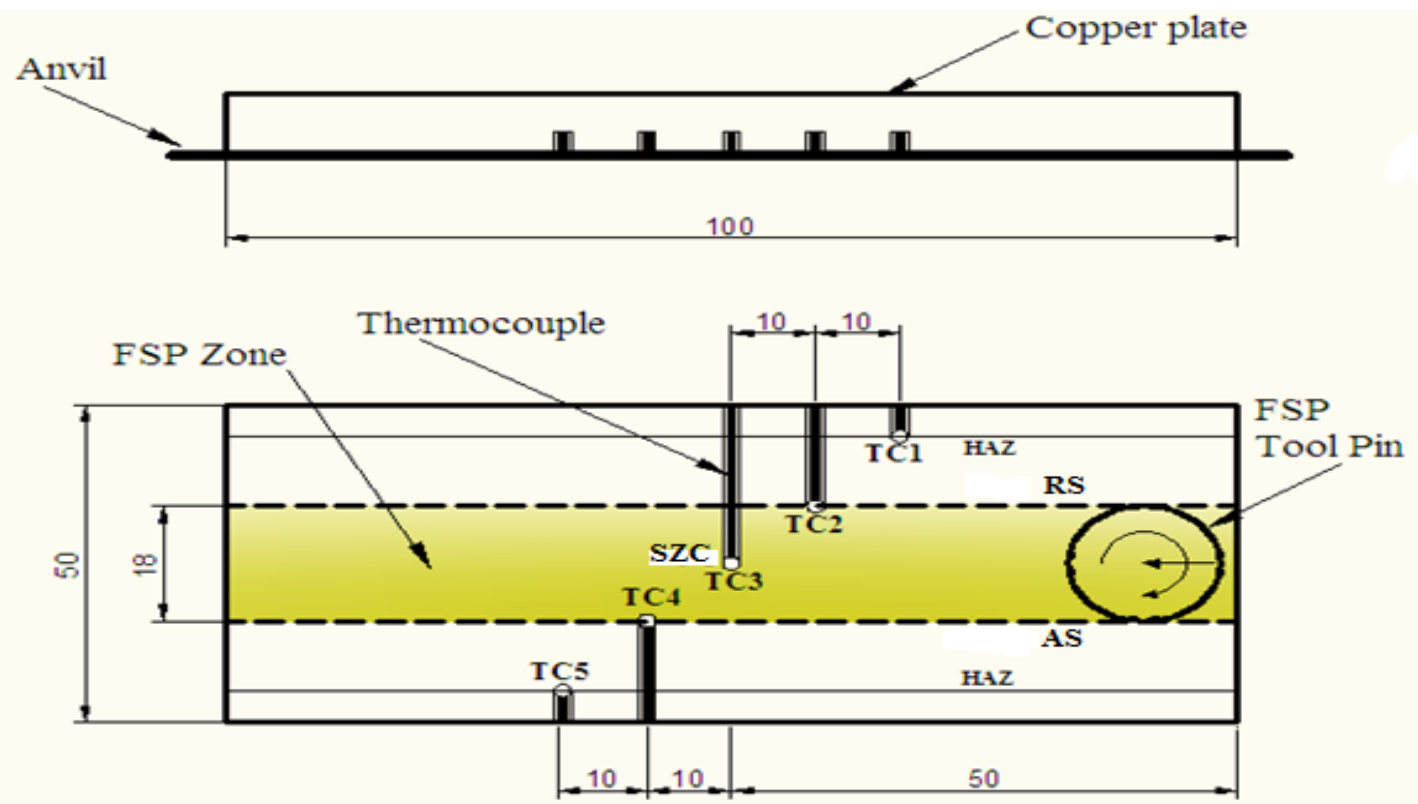

Fig.2 Schematic diagrams illustrating thermocouple locations ( SZC - Stir Zone Center, AS - Advancing Side, RS - Retreating Side, HAZ - Heat Affected Zone, TC - Thermocouple )

\section{Results and Discussion}

\subsection{External surface appearance of processed copper plates with six different tools}

Table 2 Results for six different FSP tool pin profiles at low -heat input condition

\begin{tabular}{|c|c|c|}
\hline Tool pin profiles & Photographs of the upper surface of FSP zone in copper & Comments \\
\hline $\begin{array}{l}\text { Plain cylindrical pin } \\
\text { (PC) }\end{array}$ & & $\begin{array}{l}\text { No stirring action due to low } \\
\text { rotation speed, producing } \\
\text { insufficient heat for plain pin. }\end{array}$ \\
\hline $\begin{array}{l}\text { Threaded cylindrical } \\
\text { pin (TC) }\end{array}$ & & $\begin{array}{l}\text { Surface having a reasonably good } \\
\text { finish and compression, producing } \\
\text { flash for the given plunge. }\end{array}$ \\
\hline Triflute pin (TF) & & $\begin{array}{l}\text { Better surface produced at low- } \\
\text { heat input condition and resulted in } \\
\text { less flash. }\end{array}$ \\
\hline Triangular pin (TR) & & $\begin{array}{l}\text { Insufficient movement and } \\
\text { compression of material at low- } \\
\text { heat input condition. }\end{array}$ \\
\hline Square pin (SQ) & & $\begin{array}{l}\text { Surface having reasonably good } \\
\text { finish and compression and } \\
\text { produced more heat and flash. }\end{array}$ \\
\hline Hexagonal pin (HE) & & $\begin{array}{l}\text { Good surface finish and } \\
\text { compression, producing thin flash } \\
\text { for the given plunge. }\end{array}$ \\
\hline
\end{tabular}

In this investigation the Plain cylindrical and Triangular pin produced irregular surface. Therefore, the plain cylindrical and triangular pin tools were omitted for further investigations. 


\subsection{Temperature distribution}

It is established that the thermal fields generated during FSP plays significant role in grain refinement (resulting microstructure) and properties of processed material [5]. The main objective of this work is to investigate the effects tool pin profiles on the temperature field during FSP at low heat-input condition. Fig. 3 demonstrates the temperature at various thermocouple locations across the FSP zone for four successful tools pin profile viz: Threaded cylindrical (TC), Triflute (TF), Square (SQ) and Hexagonal (HE). It can be observed that with an increase in the distance from the extreme right end of copper plate (as shown in Fig.2), the temperature rises and the peak temperature is experienced at the advancing side of the tool than at the Stir Zone Center [10].

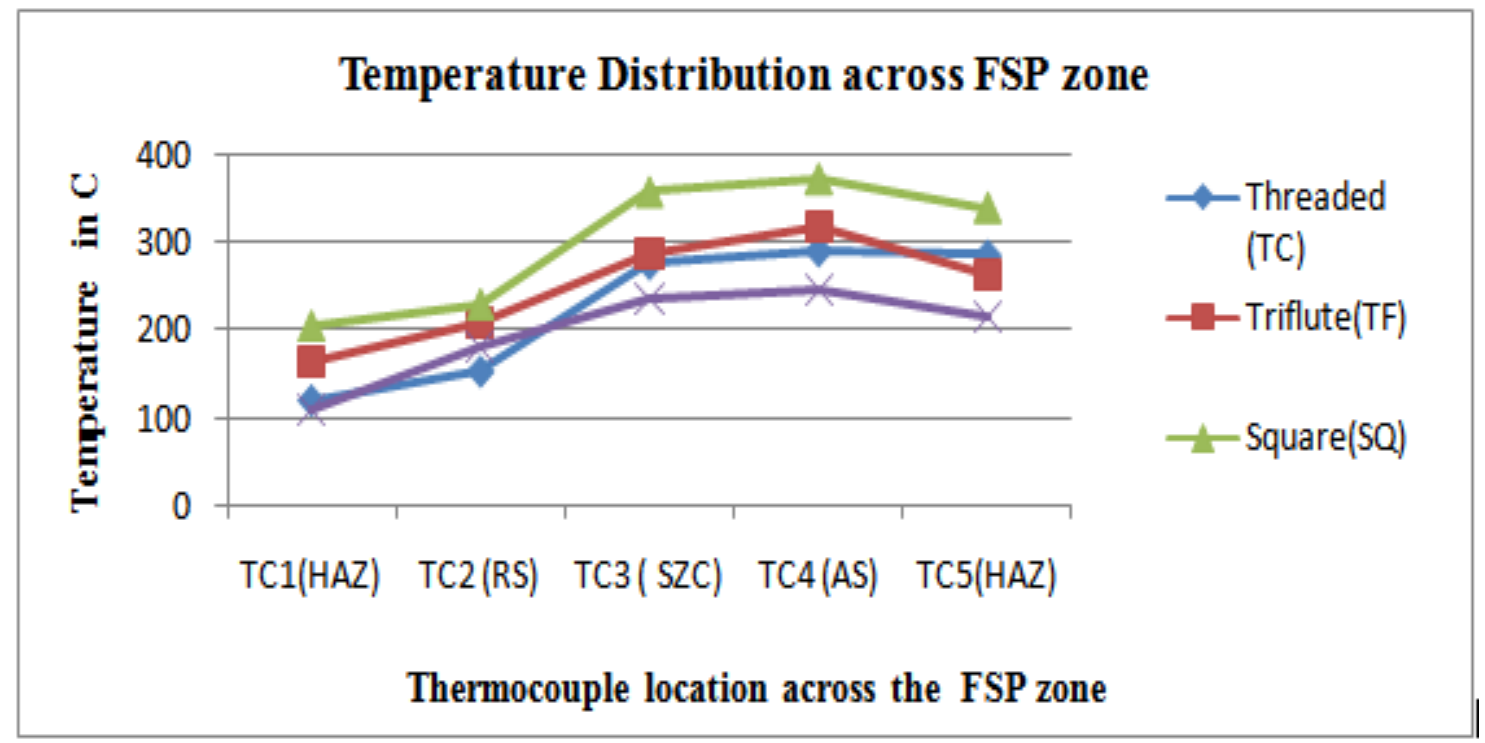

Fig. 3 Effect of pin profiles on temperature distributions

The peak temperature rise varies between $245^{\circ} \mathrm{C}$ and $370^{\circ} \mathrm{C}$ indicating that low-heat input condition occurred and no phase transformation has taken place except the material is only recrystalised [6]. The maximum temperature of $370^{\circ} \mathrm{C}$ at the advancing side of FSP zone was obtained with a square pin profile due to the stern pulsating action [3] and the low temperature of $245^{\circ} \mathrm{C}$ at the advancing side with a hexagonal pin profile for the same process parameters. During friction stir processing, the plasticized material has contact with the pin profile that also forms friction between the flowing material and the pin profile. If the contact area of the pin profile is large, then the friction with flowing material is also high. It generates more frictional heat. Thus pin contact area plays important role in heat generation in the stir zone. This study revealed that pin profiles are also responsible for heat generation along with the materials flow pattern. Further numerical investigations are needed to understand this behavior in detail.

\subsection{Microstructure Analysis}

Figure 4 shows the microstructure of the Base Metal (BM) and the Stir Zone (SZ) regions of processed samples by different successful tool pin profiles at low heat-input condition. The BM microstructure shows coarse grains with an average grain size of about $35 \mu \mathrm{m}$. The FSPed samples microstructure by Threaded cylindrical, Triflute and Hexagonal pin profile reveals finer recrystallized and equiaxed grains of about $5-10$ $\mu \mathrm{m}$ in the SZ, due to the effect of low heat-input. From Fig. $4 \mathrm{~b}$ to $4 \mathrm{e}$, it can be seen that the processed sample by hexagonal pin profile has very fine grain structure (about $5 \mu \mathrm{m}$ ) than other pin profiles. Fig. $4 \mathrm{~d}$ shows the stir zone microstructure of copper plate processed by square pin tool has enlarged grains about $20 \mu \mathrm{m}$ due to high heat generation. It can be observed that when the quantity and the exposing time of heat input are high, the rate of grain enlargement is also high. 

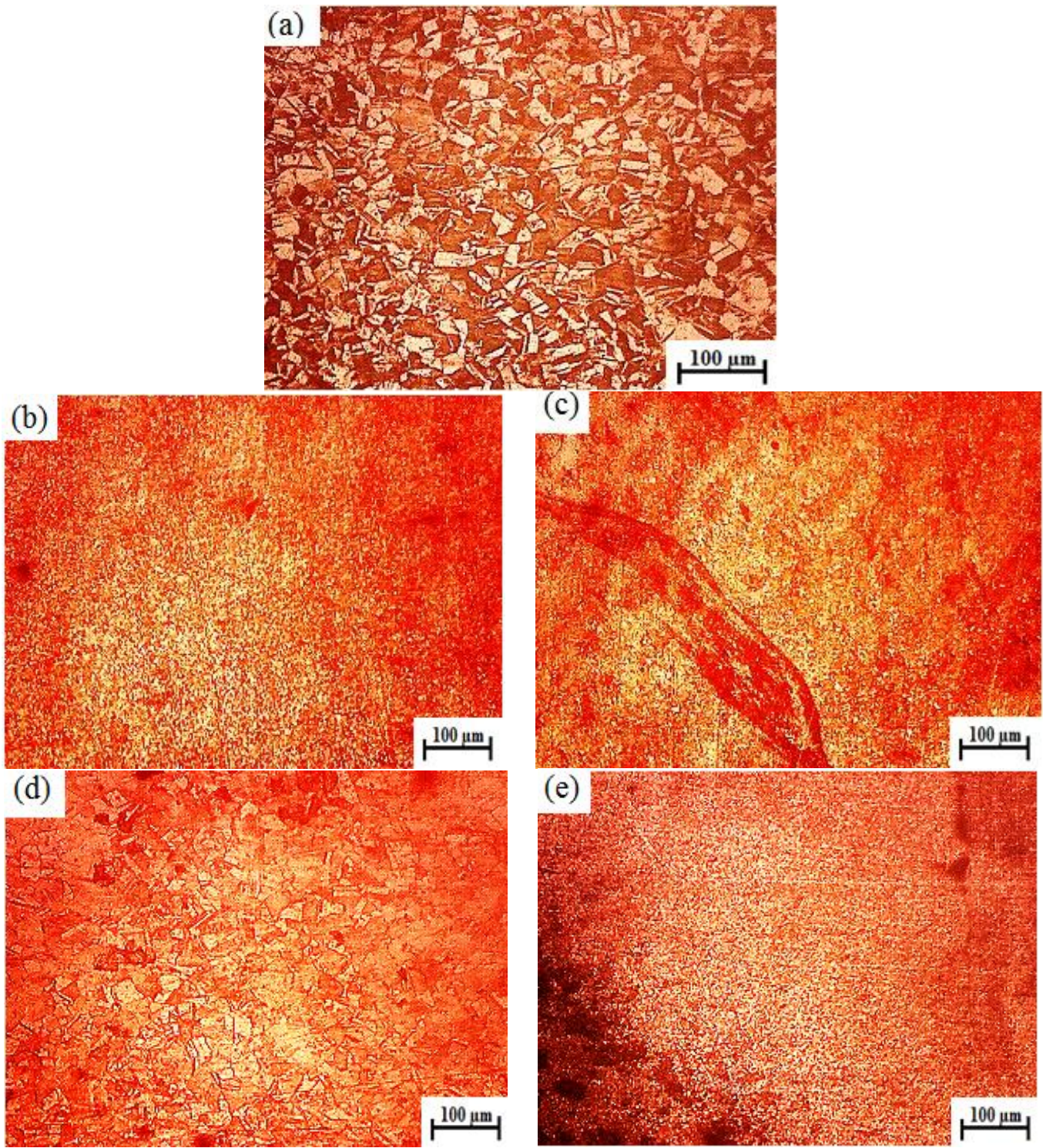

Fig. 4 Optical micrographs of (a) Base Metal and (b) - (e) stir zone regions of processed samples in (b) Threaded Cylindrical,(c) Tri Flute, (d) Square and (e) Hexagonal pin profiles.

During microstructural characterization of FSP zone, four distinct regions, i.e., Base metal (BM), Stir Zone (SZ), Thermo-mechanically affected zone (TMAZ) and Heat affected zone (HAZ), were usually identified in FSP. Fig.5a and 5b shows the typical microstructure of samples by threaded cylindrical and hexagonal pin profiles in which SZ,TMAZ and HAZ were clearly distinct.
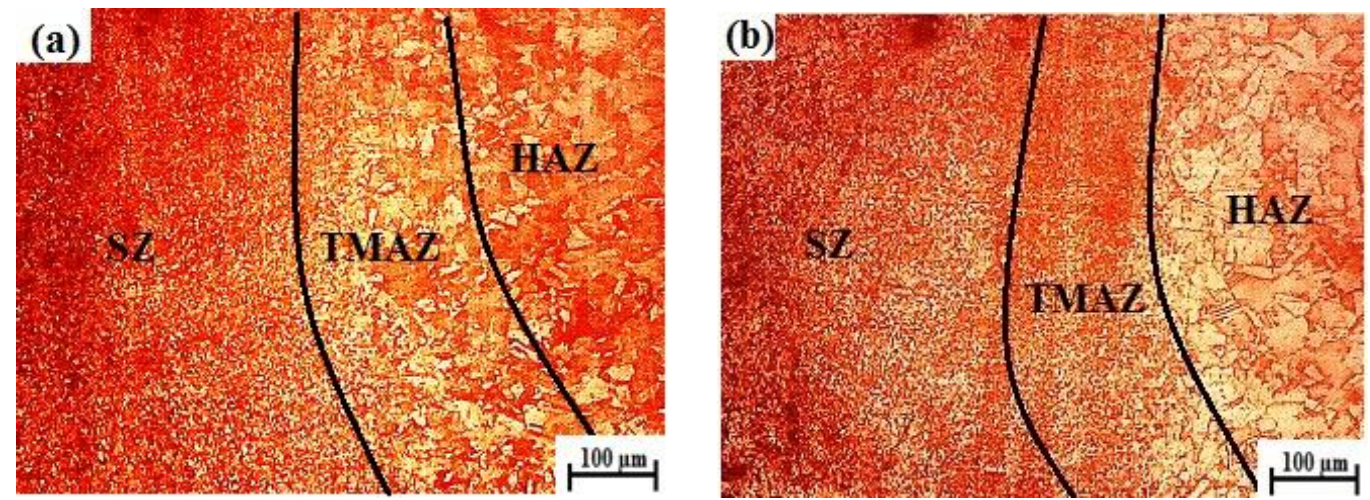

Fig.5 Microstructure of FSP samples by (a) Threaded Cylindrical (b) Hexagonal pin profile showing the SZ,TMAZ and HAZ 


\subsection{Microhardness}

The microhardness across the FSP zone was measured by Vickers microhardness tester. The base metal showed an average hardness of $82 \mathrm{Hv}$. The average microhardness values at the stir zone of the processed samples are shown in Fig. 6.

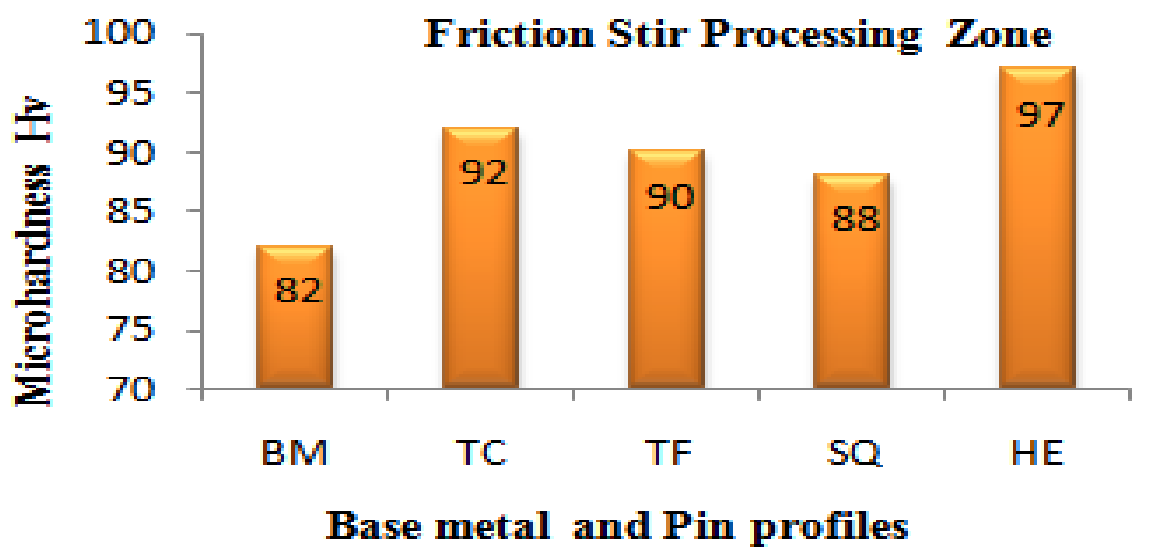

Fig. 6 Effect of pin profiles on processed zone hardness

The microhardness of the processed copper plates was normally influenced by heat generation and subsequent grain refinement. Fig. 3 had shown the heat input values of different tools at various zones of processed copper plates. High heat input during processing leads to grain growth in stir zone. The grain growth in stir zone subsequently reduces the microhardness value. The square pin profile generated more heat $\left(370^{\circ} \mathrm{C}\right)$ due to its higher pulsating stirring action [9] and it has lower microhardness (88Hv) than other pin profiles. The hexagonal pin tool provided low heat generation of $245^{\circ} \mathrm{C}$ compared to other types of tool and it has higher microhardness value compared to others. The micrograph [Fig.4e] shows the stir zone of copper plate processed by hexagonal pin tool shows refined grains (about $5 \mu \mathrm{m}$ ) due to the effect of low heat input. Thus, increase in heat input increases the grain growth and subsequently decreases the microhardness of the processed copper plates. Therefore, the heat input and exposing time are governing the grain growth and subsequent changes in hardness.

\subsection{Tensile behaviour}

Tensile properties of base metal and successful FSP samples such as ultimate tensile strength (UTS), yield strength (YS) were listed in the Table 3. The tensile strength of the processed copper plates were depends on the mechanical mixing at the stir zone. Heat generation during mechanical mixing also plays important role for better mixing of plasticized materials in the stir zone. Heat generation at stir zone improves the mechanical mixing by increasing the plasticity of deforming materials during mechanical stirring. Increase in heat input increases the plasticity of the deforming materials. However, high heat input results in softening of materials in stir zone. Pin profiles influenced the mechanical mixing and heat generation at the stir zone [11]. The Copper plates processed with threaded pin tools show higher tensile strength than other tools. This was due to the proper material flow between the threads which facilitates the good mechanical mixing. The copper plates processed by square pin tool show second higher tensile strength values. The proper mechanical mixing was occurred in square pin tools due to their pulsating action. In case of triflute pin tools, the processing materials get stick and sealed the flutes which restricts pin to move the plasticized materials around it. This leads to low mechanical mixing at stir zone. In case of hexagonal pin tool, the mechanical mixing was very low due to very low pulsating action. However, the tensile strength of the processed copper plates show inferior tensile strength compared to base material due to softening at stir zone during friction stir processing.

Table 3 Tensile and Yield strength values of base metal and friction stir processed copper plates

\begin{tabular}{lcc}
\hline \multicolumn{1}{c}{ Samples } & Tensile Strength (MPa) & Yield Stength (MPa) \\
\hline Base metal (BM) & 279 & 271 \\
\hline by Threaded Cylindrical pin tool(TC) & 228 & 209 \\
\hline By Square pin tool (SQ) & 207 & 203 \\
\hline by Triflute pin tool (TF) & 196 & 196 \\
\hline by Hexagonal pin tool (HE) & 165 & 163 \\
\hline
\end{tabular}




\section{Conclusion}

The effect of heat input on mechanical properties of the pure copper plates friction stir processed by different FSP tool pin profiles were investigated in this study. The observations of this investigation are summarized below.

1. Of the six tool pin profiles used to form FSP zones on copper plate, the four pin profiles (threaded cylindrical, triflute, square and hexagonal) show successful formation of FSP surface on copper. Among the four, the hexagonal and threaded pin profiles exhibit good surface finish.

2. The temperature field across the FSP zone is asymmetric with slightly higher temperatures on the advancing side (AS) of the tool in copper plate.

3. Square pin profile caused higher degree of plastic deformation which resulted in maximum temperature rise of $370^{\circ} \mathrm{C}$ at the advancing side of FSP zone.

4. The microhardness of the processed copper plates was influenced by their grain sizes. The grain sizes were monitored by heat input during processing. High heat generation leads to grain growth in the stir zone which lowers the microhardness values.

5. Pin profiles are also responsible for heat generation during processing at stir zone. If the contact area of the pin is more with flowing material, then generation of frictional heat is also more.

6. Tensile properties of the processed copper plates depend on the heat input and subsequent mechanical mixing in stir zone. Threaded and square pin profiled tools show better mechanical mixing and better tensile strength values.

\section{References}

[1]. R.S.Mishra, Murray W.Mahoney (2007), Friction stir welding and processing, E-publishing, ASM International.

[2]. Z.Y.Ma (2008), Friction stir processing technology: A review, Metallurgical and Materials Transactions A, Vol.39A ; 642-657.

[3]. K. Elangovan , V.Balasubramanian (2007), Influences of pin profile and rotational speed of the tool on the formation of friction stir processing zone in AA2219 aluminium alloy. Materials Science and Engineering A 459 ; 7 -18.

[4]. M.Karthikeyan, A.K. Shaik Dawood (2012), Influence of tool design on the mechanical properties and microstructure in friction stir welding of AA6351 aluminium alloy. Engineering Science and Technology: An International Journal, Vol.2, No.2 ; $233-237$.

[5]. B.M.Darras, M.A.Omar, M.K. Khraisheh (2007), Experimental thermal analysis of friction stir processing. Material Science Forum, Vols.539-543; 3801-3806

[6]. L.Karthikeyan, V.S. Senthilkumar, V. Balasubramanian, S. Natarajan (2009), Mechanical property and microstructural changes during friction stir processing of cast aluminium 2285 alloy. Materials and Design 30 ; 2237-2242.

[7]. G.M.Xie, Z.Y. Ma, L. Geng (2007), Development of a fine-grained microstructure and the properties of a nugget zone in friction stir welded pure copper. Scripta Materialia, 57,;73-76.

[8]. H. Khodaverdizadeh, A. Heidarzadeh, T. Saeid (2013), Effect of tool pin profile on microstructure and mechanical properties of friction stir welded pure copper joints. Materials and Design $45 ; 265-270$.

[9]. K.Surekha, A. Els-Botes (2011), Development of high strength, high conductivity copper by friction stir processing. Materials and Design $32 ; 911-916$

[10]. S.Srinivasan, K. Oh-Ishi, Alexander P.Zhil Yaev, Christian B.Fuller, Blair London, Murray W. Mahoney, Terry R.Mcnelley (2010), Peak stir zone temperatures during friction stir processing. Metallurgical and Materials Transactions A, Vol.41, Issue 3 ; 631-640.

[11]. L. John Baruch, R. Raju, V. Balasubramanian (2012), Effect of tool pin profile on microstructure and hardness of friction stir processed aluminium die casting alloy. European Journal of Scientific Research, Vol.70, No.3 ; 373-385. 